\title{
Editorial
}

\section{Temporary cardiac pacing}

Temporary cardiac pacing can be a life-saving manoeuvre. The indications and techniques are well established. ${ }^{1}$ The procedure is one of the 'essential' components of the training programme in general internal medicine. This may be desirable, but is it wise nowadays? Is it achievable?

The traditional indication for a temporary cardiac pacemaker is heart block; the usual venue for the procedure is a treatment room alongside a coronary care unit (CCU). Most patients have threatened or actual high-grade transient atrioventicular (AV) block in association with acute myocardial infarction. Some will have Stokes-Adams attacks or established AV block which is sufficiently symptomatic to warrant urgent treatment pending the insertion of a permanent pacing system. For these patients, physicians with on-take responsibilities are required to learn the technique. Most physicians, however, lack the opportunity to maintain their skill. In Cambridge, for example, the number of temporary electrodes inserted in the CCU has dwindled year by year from 57 in 1994, to 29 in 1998; the numbers of procedures performed out of hours were, respectively, 29 and 10. Every hospital has seen a substantial increase in the number of senior medical staff. Many will admit that they have not inserted an electrode for a year or more, and would be nervous of doing so. Corridor conversations should not initiate policy changes, but they may prompt scrutiny of current practice.

The reason for this decline is likely to be due in part to decreased need. The past decade has seen a huge change in the management of patients suffering from acute coronary syndromes. The introduction of thrombolytic treatment and the emphasis on rapid admission to hospital has meant that major infarcts are commonly aborted, and damage to the conduction system is rare. Supportive medical measures are more effective, and in particular anti-arrhythmic drugs are generally avoided. Perhaps also, physicians who no longer feel comfortable with the technique will tend to postpone a decision until recovery or death occurs.

There is nevertheless still a need for the skill. Patients with inferior myocardial infarcts who are expected to recover and victims of frequent Stokes-Adams attacks would be two such examples. The latter group are subsequently transferred to a specialist centre, often fearful of receiving a permanent system because the previous experience was so unpleasant. Multiple stab wounds, haematomata, and failure to pace are all too frequent complications. This was documented a decade ago in a study from Oxford of 145 patients, 36\% of whom had at least one major problem. This finding has been amply corroborated since. ${ }^{2-4}$ It is known that most procedures are performed by junior doctors, few of whom have received adequate training or supervision. ${ }^{34}$ Infection is a particular problem in those patients whose electrodes remain in situ for more than 48 hours - septicaemia developing in 10 of 53 patients in one series. ${ }^{4}$ The patient who has had to wait to be transferred for a permanent system is especially vulnerable to this complication; the ensuing implant is in turn more likely to become infected which adds further to the suffering, and expense. ${ }^{56}$

Complications of temporary pacemaker procedures continue to be reported in this and other journals. ${ }^{78}$ Audit of temporary pacing is generally undertaken as part of a CCU audit but the numbers are too small to permit useful recommendations We have evidence, however, that senior house officers (SHOs) and house officers usually learn from registrars and undertake on average 2.3 supervised procedures prior to independent practice, ${ }^{7}$ a figure that would be difficult to justify to a court of law. Most junior medical staff will rotate through specialist cardiac centres but even there precious few temporary electrodes are inserted; when they are it is usually because there has been a complication of the conventional approach, and hence the femoral route is chosen; under those circumstances a senior operator should perform the procedure. To have SHOs undertake the venous access part of a permanent system is certainly possible but the technique is rather different since the cephalic vein cutdown or subclavian stab is performed through an open incision. Cardiology SHOs generally obtain some experience of cardiac catheterisation and electrophysiology but this invariably involves the femoral approach. Registrars are not going to have received sufficient training in the technique, unless they are enrolled in a cardiovascular training programme. How then is the service to be provided?

An easier question to answer is what cannot be provided. We can no longer expect today's general physician to be responsible for temporary pacemakers, nor should his junior staff be undertaking the procedure without cardiological supervision. There are not enough cardiologists outside specialist centres and large District General hospitals to provide an adequate service; most smaller hospitals have one physician with an interest in cardiology and we cannot expect them to be on permanent call. Yet that is where the problem is most likely to be encountered and where the complication rates are highest. ${ }^{2}$ These hospitals are, however, well staffed with anaesthetists who are adept at gaining central venous access either through percutaneous subclavian or internal jugular venepuncture. Anaesthetists are generally regarded as being most proficient in placing central lines for other purposes, even in cardiological practice, for example, intravenous antibiotics in the treatment of endocarditis. The other element of the technique, namely positioning the electrode tip in a satisfactory position in the right ventricle, would remain a problem. A possible solution lies in the use of balloon-flotation catheters; early experience has yielded very satisfactory results ${ }^{8}$ with shorter procedure times and fewer suboptimal positions. Subject then to several provisos, the temporary pacing in smaller hospitals might be best organised by a collaboration between the departments of cardiology and anaesthesia.

The dilemma posed by problems of temporary cardiac pacing is part of a more general difficulty which has to be faced by those planning medical services in the UK. The concept of the general physician lives on, yet it is an anachronism which inhibits the development of specialist medicine, and the acceptance of acute medicine as a discipline. For that is what general medicine has become. A Certificate of Completion of Specialist Training (CCST) in acute medicine and relevant specialty would make good sense. The Calman reforms have helped to clarify thinking on this issue by defining the necessities of a training programme. The general (internal) medicine essential procedures include sigmoidoscopy, lumbar puncture, and intercostal drain insertion, in addition to temporary cardiac pacing. For the last of these skills it would appear that it is no longer wise nor feasible to train all specialist registrars seeking a CCST in general medicine. What about the oth- 
ers, one wonders? And even if the technique of sigmoidoscopy can be taught safely, is the registrar whose prime interest is cardiology going to be a competent observer? Reshaping the practice of medicine in the UK is inevitable, as has already happened in many other developed countries where specialist practice dominates. Patients in this country and in Europe will expect a physician's performance to be as overtly competent as a surgeon's. Data on the number of procedures performed and the number with complications may have to be made available.

Whenever possible temporary pacing should not be undertaken prior to permanent pacing in a specialist centre; emergency transfer should be arranged. Cardiologists

1 Fitzpatrick A, Sutton R. A guide to temporary pacing. BMF 1992; 304:365-

2 Winner SJ, Boon NA. Clinical problems with temporary pacemakers prior to permanent pacing. f $R$ Coll Physicians Lond 1989;23:161-3.

3 Andrews R, Skehan JD. Temporary pacing: continuing failures in medical management. Br Heart $\mathscr{f} 1992 ; 68: 91$.

4 Murphy JJ. Current practice and complications of temporary transvenous Murphy JJ. Current practice and comp

cardiac pacing. BMF 1996;312:1134.
Chauhan A, Grace AA, Newell SA, et al. Early complications after dual chamber pacemaker implantation. Pacing Clin Electrophysiol 1994;17:2012-5. in small district hospitals should discuss alternative methods of providing the service with their colleagues in the department of anaesthesia. And temporary cardiac pacing should no longer be an essential procedure of the training in general medicine.

M C PETCH

Consultant Cardiologist, Papworth Hospital, Papworth Everard, CB3 8RE, UK

Accepted 5 May 1999

Keywords: cardiac pacing
6 Aggarwal RK, Connelly DT, Ray SG, Ball J, Charles RG. Early complications of permanent pacemaker implantation: no difference between dual and single chamber systems. Br Heart 7 1995;73:571-5.

7 Wheatcroft S, Maxwell S. Letter. F R Coll Physicians Lond 1997;31:111.

8 Bajaj BPS, Evans KE, Thomas P. Postpericardiotomy syndrome following temporary and permanent transvenous pacing. Postgrad Med $\mathcal{7}$ 1999;75: $357-8$.

9 Ferguson JD, Banning AP, Bashir Y. Randomised trial of temporary cardiac pacing with semigrid and balloon flotation electrode catheters. Lancet 1997; 349:1883.

\section{Images in medicine}

\section{Splenic tuberculosis}

A 33-year-old woman was admitted for surgical drainage of a peri-anal abscess. No other significant problems were reported and her chest radiograph was normal. In spite of adequate surgical drainage, her swinging pyrexia continued. Ultrasound and abdominal computed tomography (CT) scan (figure 1) showed numerous ill-defined hypoechoic and hypodense lesions in the spleen.

Her HIV-test was positive. No other source for her fever was identified. Despite antituberculous treatment for 3 weeks the high fever continued. It was felt splenectomy was indicated.

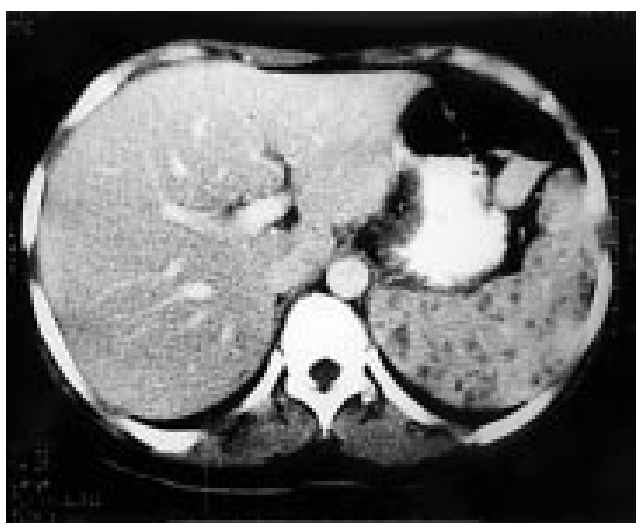

Figure 1 Abdomen CT scan showing multiple intrasplenic hypodense lesions
The intra-abdominal findings were unremarkable except for a slightly enlarged spleen with a myriad of yellowish nodules protruding through the splenic capsule (figure 2). Histology confirmed tuberculosis of the spleen. Postoperatively the temperature returned to normal and the patient was discharged 5 days later on antituberculous treatment. Six months after the operation the patient is well.

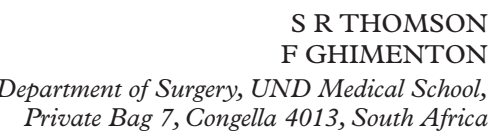

Private Bag 7, Congella 4013

Accepted 26 April 1999

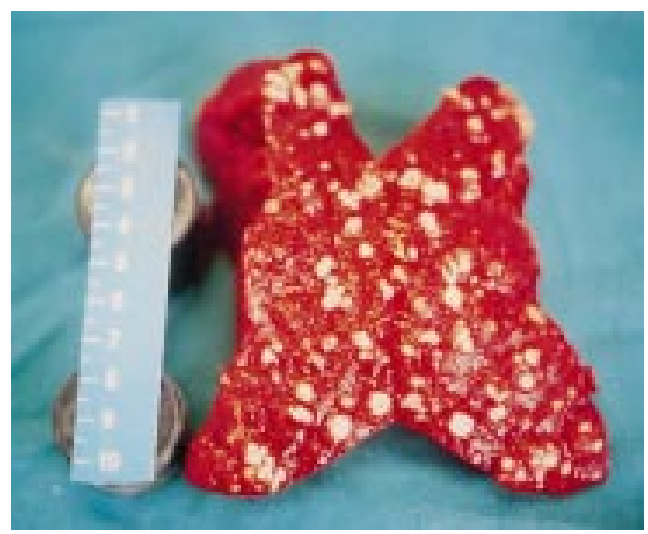

Figure 2 Bisected spleen demonstrating multiple tuberculous nodules 